$$
\begin{aligned}
& \text { تأثير سرعة دوران القالب في الخواص الميكاتيكية } \\
& \text { لمواد متر اكبة بوليميرية متدرجة وظيفياً } \\
& \text { أحمد أكرم عبل الله ج جامعة الموصل/ كلية الهندسة / قسم الهندة الميكانيكية. عواد هلوش خضر } \\
& \text { الخلاصة }
\end{aligned}
$$

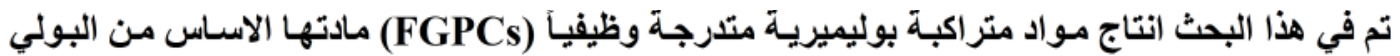

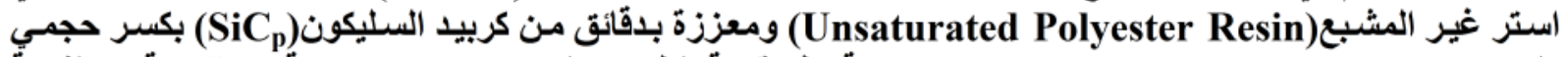

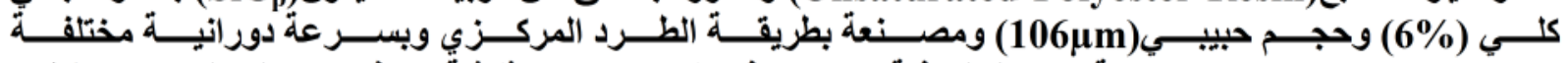

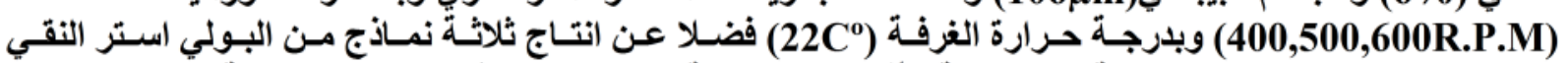

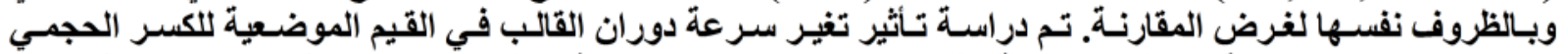

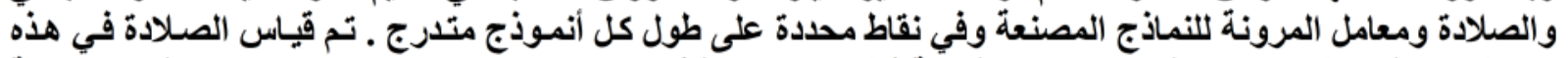

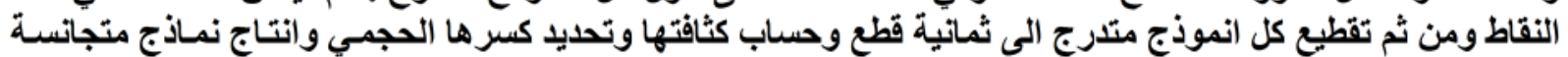

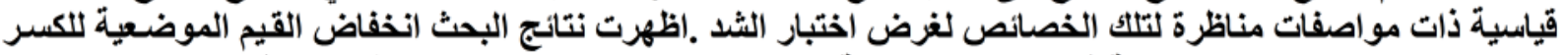

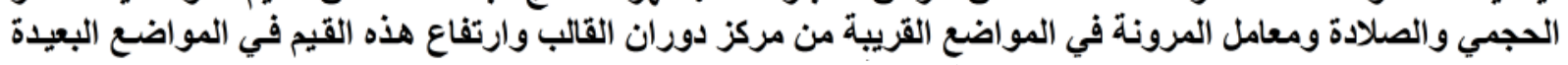$$
\text { مع زيادة المواضع }
$$

\title{
The Effect of Mold Rotational Speed on Mechanical Properties of Functionally Graded Polymeric Matrix Composites
}

Ahmed Akram Abdullah

\section{Awad Hallosh Khidhir}

Assistant Professor

University of Mosul/College of Engineering/Mechanical Engineering Department

\section{Abstract}

In this research, a functionally graded polymeric matrix composites (FGPMCs) were produced using centrifugal casting method. These composites were fabricated from unsaturated polyester resin as a matrix and reinforced with silicon carbide particles $\left(\mathrm{SiC}_{\mathrm{p}}\right)$ of $(\mathbf{1 0 6} \mu \mathrm{m})$ and $(6 \%)$ bulk volume fraction, using different mold rotational speeds(400,500,600 R.P.M) at room temperature (22C $)$. Additional (3) samples of pure polyester were manufactured at the same conditions for comparison purpose . The aim of the present research was to study the effect of mold rotational speed on local values of volume fraction, hardness and Young modulus at specific points along the graded samples. Hardness was measured at these points then graded samples were cut to eight portions. Density and volume fraction were evaluated, then standard homogenous samples of constant but different volume fraction were manufactured. Results shows that local values of volume fraction, hardness and Young Modulus decreased in nearby positions of the center of rotation and increased in positions far away from the center of rotation with increasing mold rotational speed.

Key words: Functionally graded polymeric composite, hardness, modulus of elasticity, mold rotational speed. 


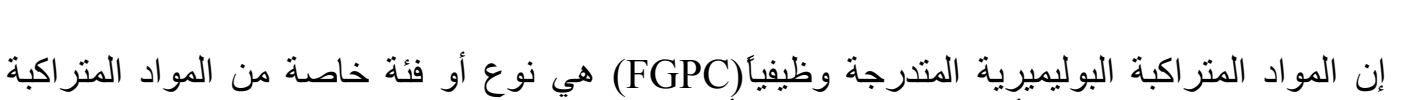

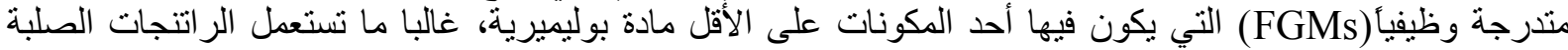

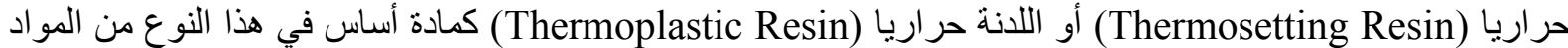

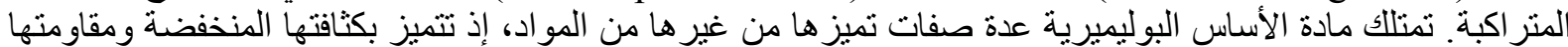

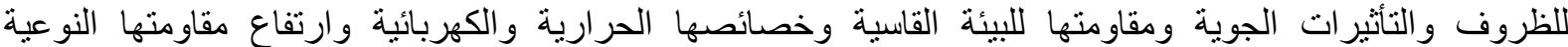

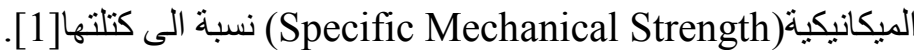

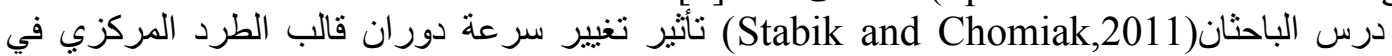

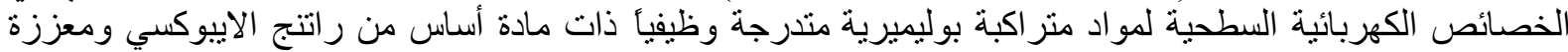

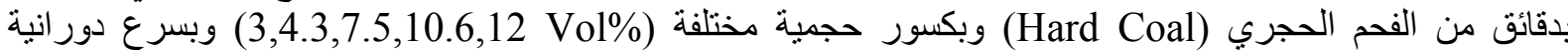
مختلفة(535-617 R.P.M) .أهمية هذه المو اد تكمن في الحصول على مواد عازلة كهربائياً في أحد الجوانب وموصلة

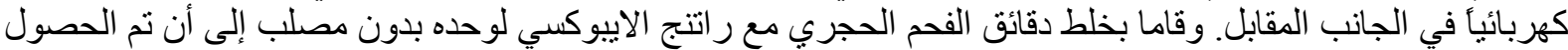

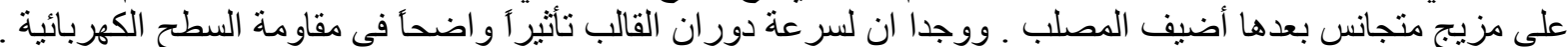

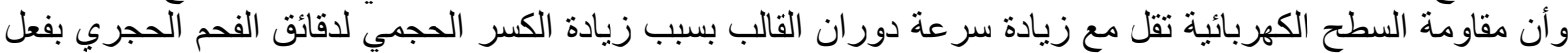

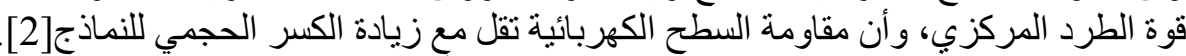

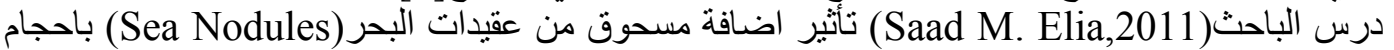

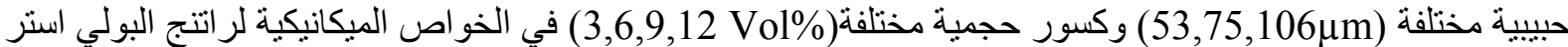

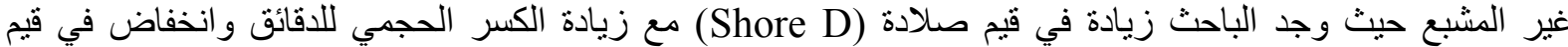

الصلادة مع زيادة الحجم الحبيبي [3]. درست الباحثة (نوال عزت ،2009 ) تأثثير سرعة دوران قالب الطرد المركزي والكسر الحجمي لدقائق

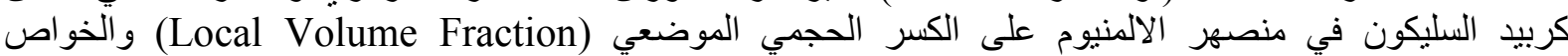

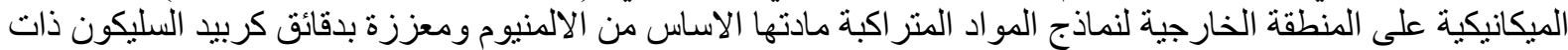

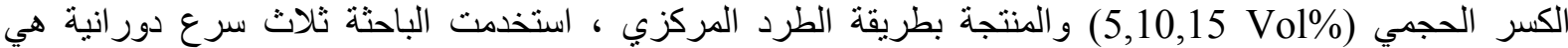

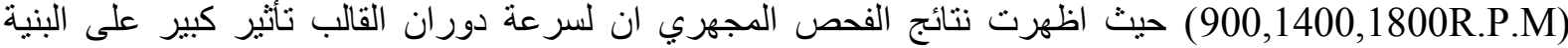

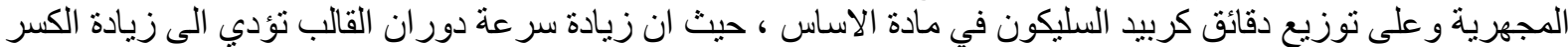

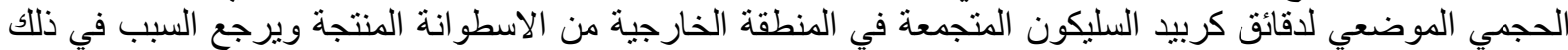

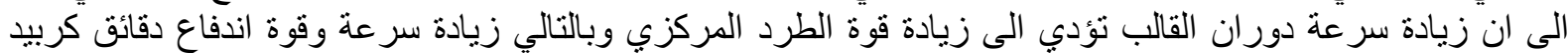

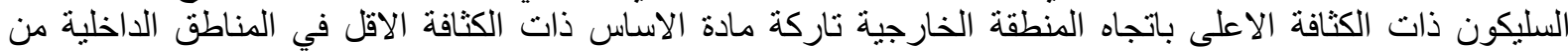

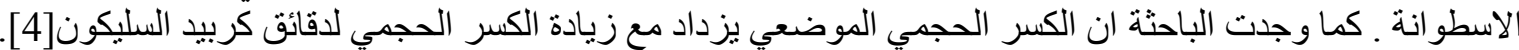

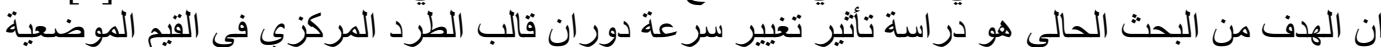
للكسر الحجمي لدقائق كربيد السليكون (SiC) و الصلادة ومعامل المرونة لمادة متر اكبة بوليميرية متدرجة وظيفي الئياً اساسها

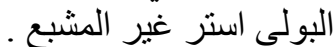

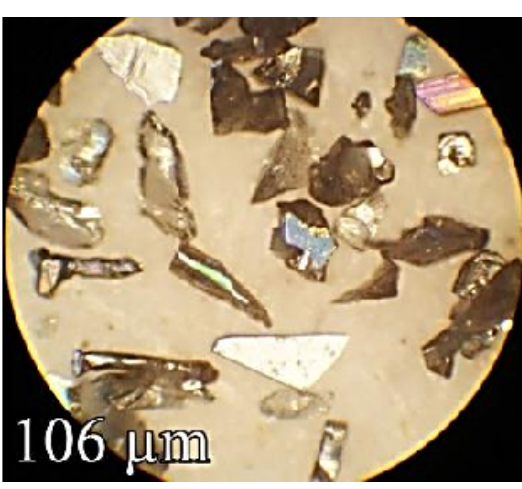

الثكل(1):صورة مجهرية تبين دقائق كربيد السليكون المستعملة في تونين

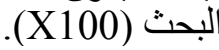

تم استخدام راتتج البولي استر غير المشبع) Unsturated

Poliya Composite ) و المصنع من قبل شركة التركة (Polyester Resin ( Resins and Polymers,Inc.

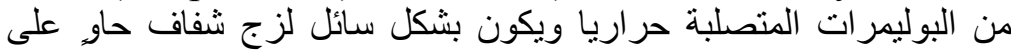

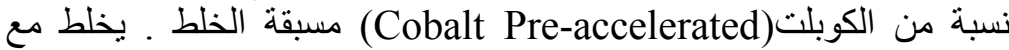
Methyl Ethyl Ketone Peroxide ) المصلب بيروكسيد مثيل اثيل كينون Akpa Organic Peroxides, ) المنتج من قبل شركة (MEKP (Initiators \& Paint Driers

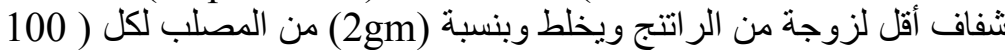

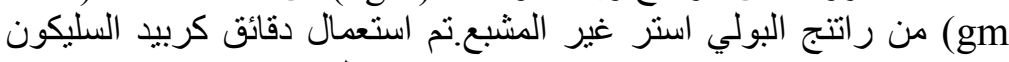
كمادة معززة ، رمزها الكيمياوي (SiC) (Silicon Carbide)

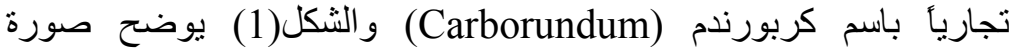
مجهرية للاقائق المستعملة في البحث. 
: تأثير سرعة دوران القالب في الخواص الميكانيكية لمواد متراكبة بوليميرية متدرجة وظيفياً

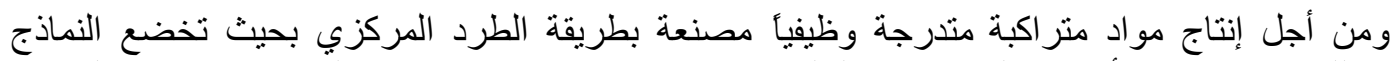

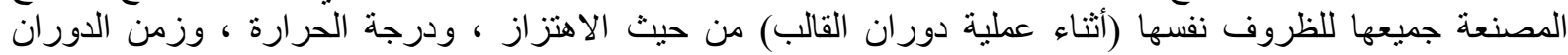

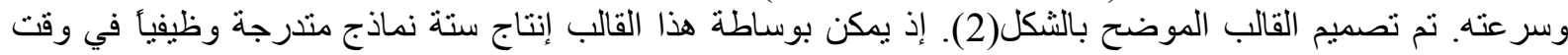
واحد وبالظروف نفسها [5]. يتكون هذا القالب من ثلاث طبقات ، الطبقة الوسطى تحتوي على الأخاديد التي سوف نشكل الأنموذج

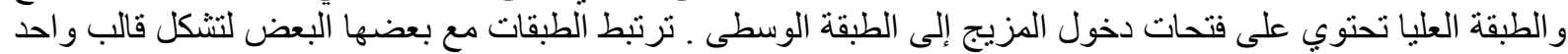

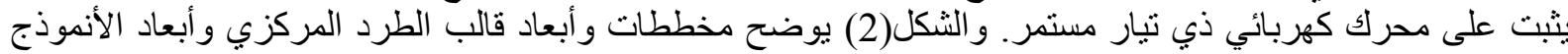

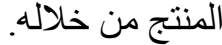

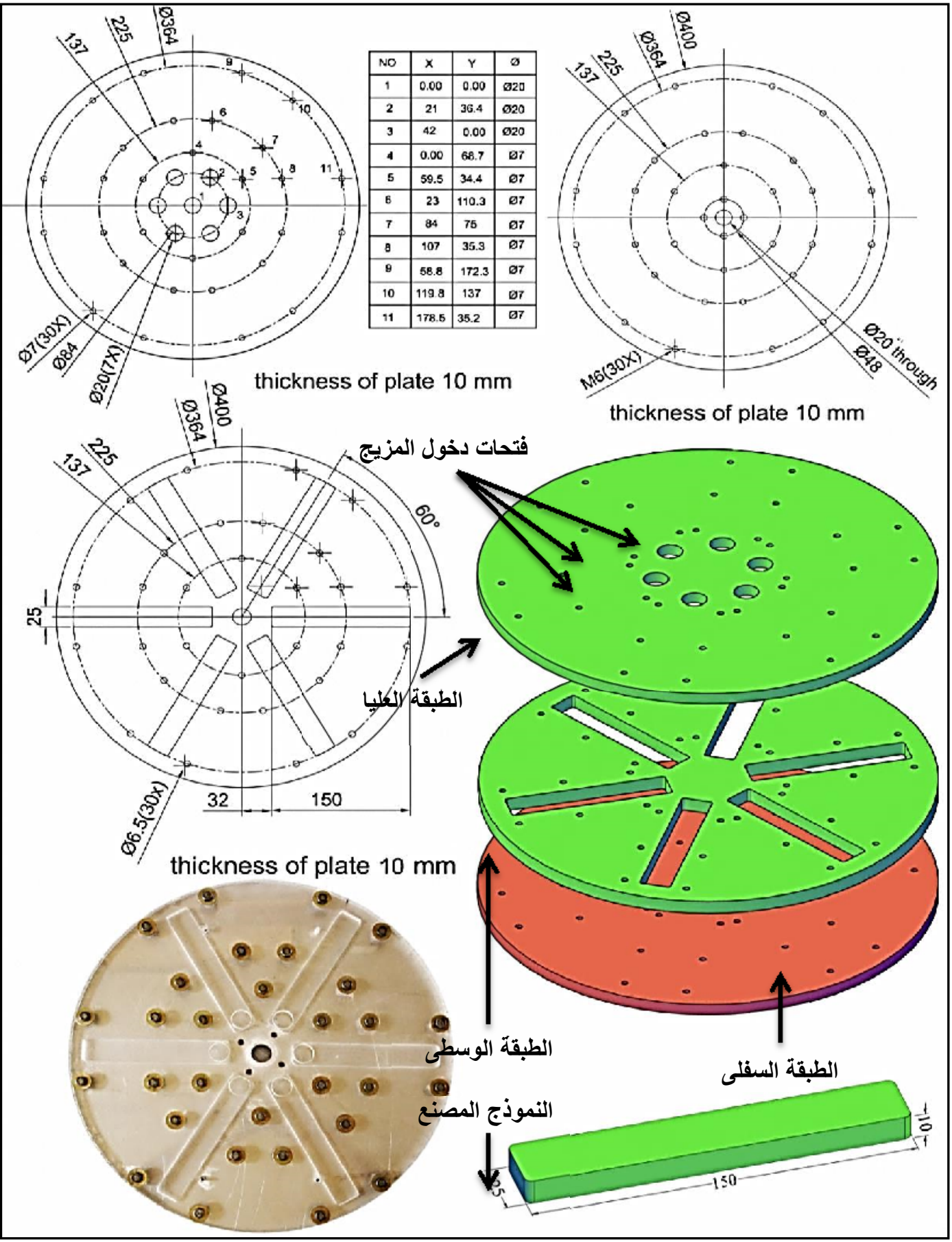

الثكل(2):قالب الطرد المركزي المستعمل في البحث و الأنموذج المصنع (كافة الابعاد بالمليمنر)(5]. 
يثبت القالب الموضح في الثكل(2) على محرك كهربائي يتم السيطرة على سر عته عن طريق منظم فولتية .

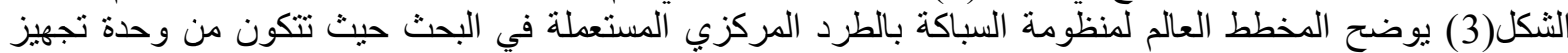

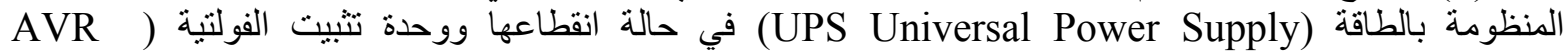
(Automatic Volte Regulator متناوبة الى مستمرة(Bridge Rectifier) لتكون مناسبة لعمل المحرك.

بعد حساب وزن كل مكون من مكونات الأنموذج يتم خلط الر اتتج(Resin) لوحده مع الدقائق يدويأ وبسر عة بائق

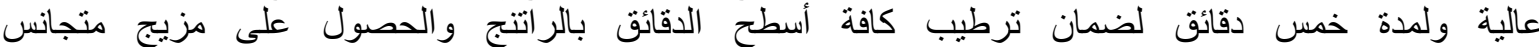

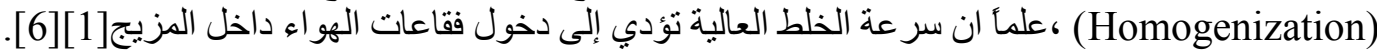

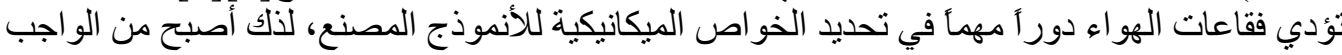

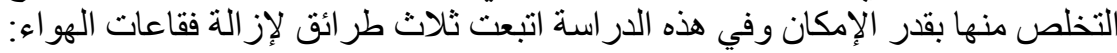

او لا : تقليل لزوجة الر اتتج عن طريق رفع درجة حر ارته إلى (40 C C ألثاء

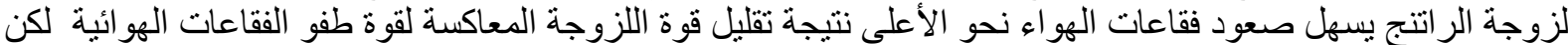

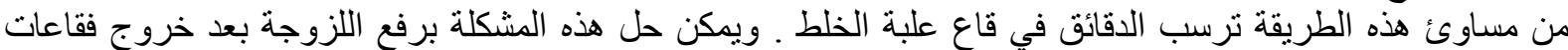

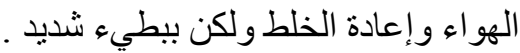

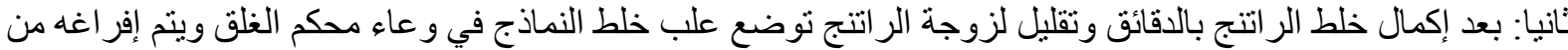

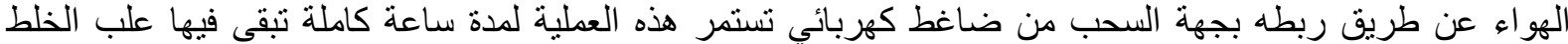

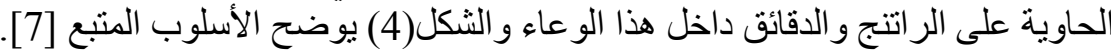

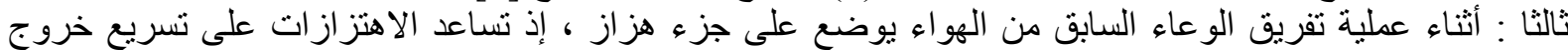

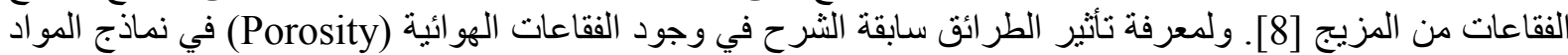

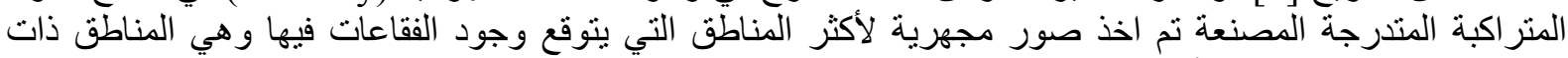

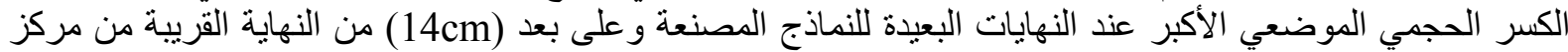
الدور ان وللسرع الدور انية الثناثة (400,500,600 R.P.M) و الثكل(5) يوضح صور مجهرية لهذه الئناطق تبين خلوها من الفقاعات الهو ائية.

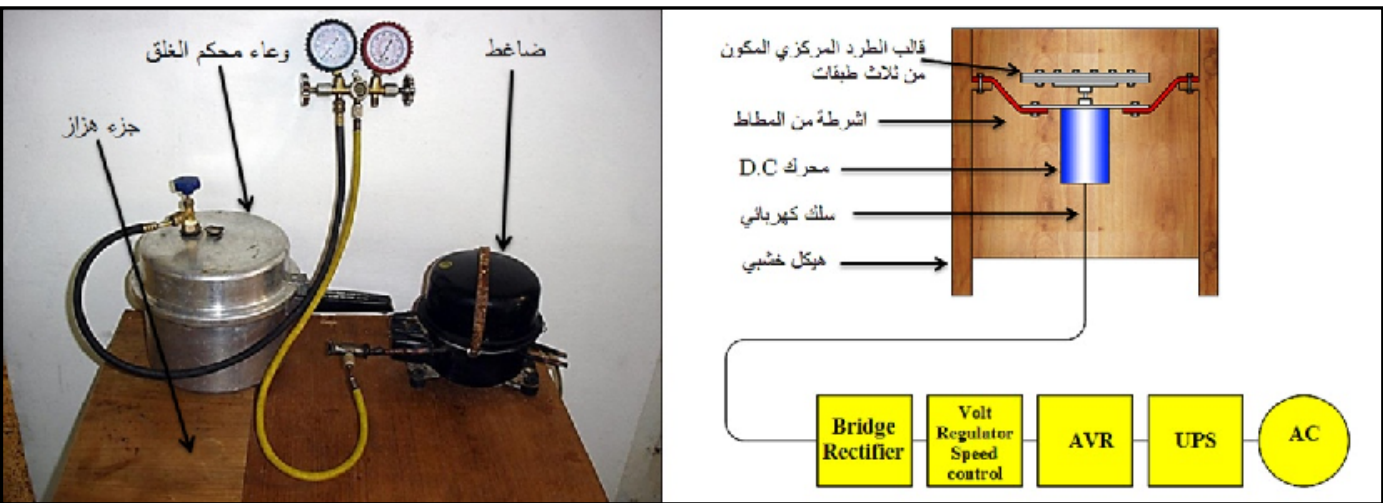

$$
\text { التَكل(3): المخطط العام لمنظومة السباكة بالطرد التُكل(4): الاسلوب المتبع في إخر اج }
$$

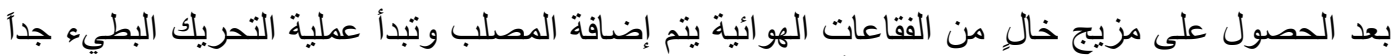

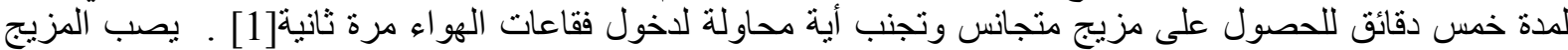

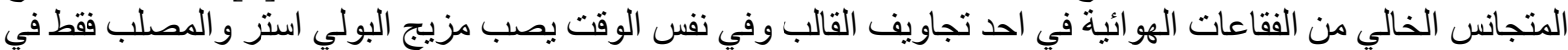

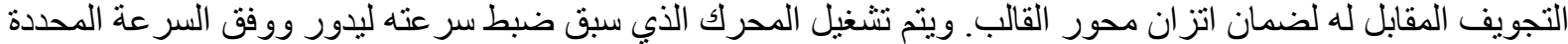
ولمدة (30) ثانية . تترك النماذج داخل القالب لمدة (24) ساعة لضمان اكتمال تصلب النماذج داخل القالب [8]. بعدها يتم

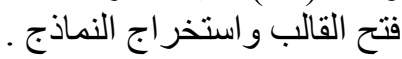


: تأثير سرعة دوران القالب في الخواص الميكانيكية لمواد متراكبة بوليميرية متدرجة وظيفياً

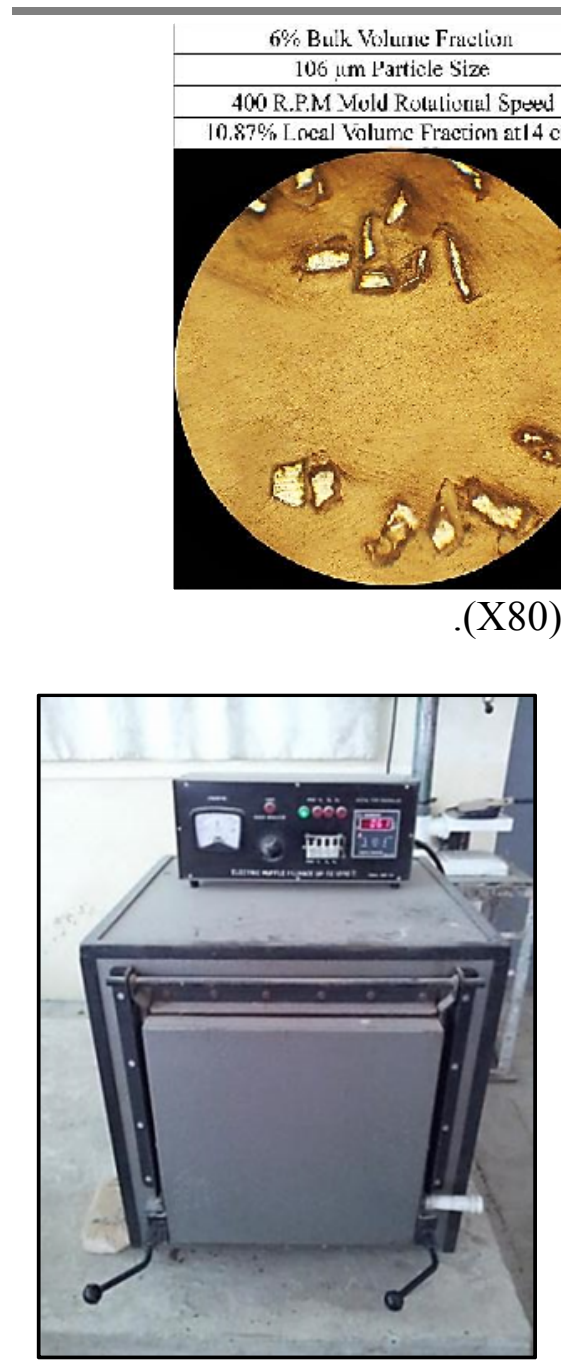

الثكل(6):الفرن الكهربائي

المستخدم لإكمال عملية البلمرة.
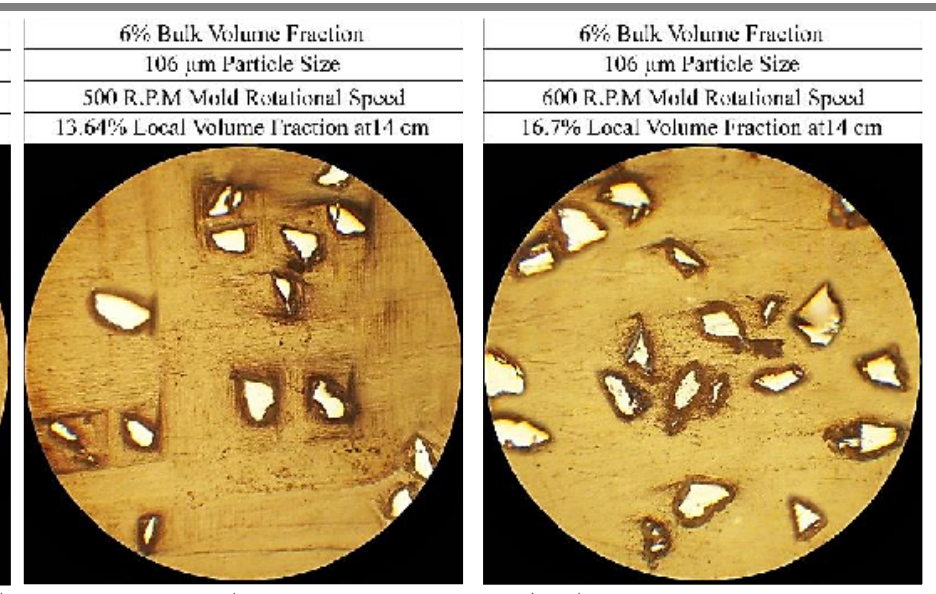

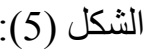

6\% Buik Whum Fraction
.

توضع النماذج بعد استخر اجها من القالب في فرن كهربائي درجة

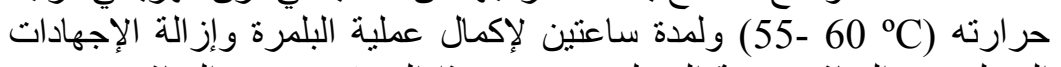

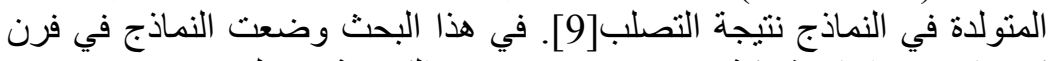

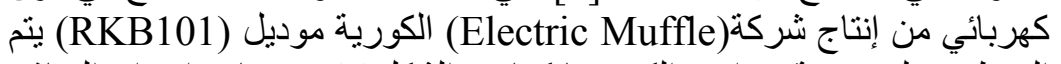

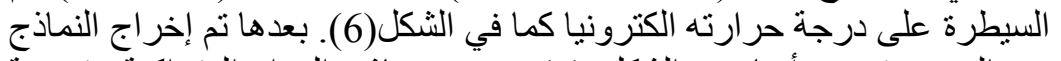

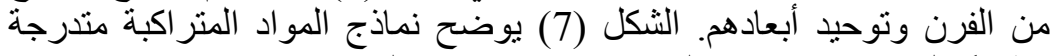

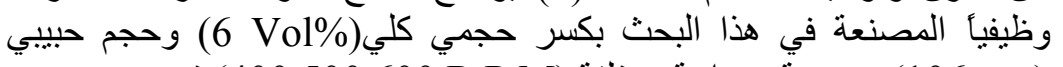

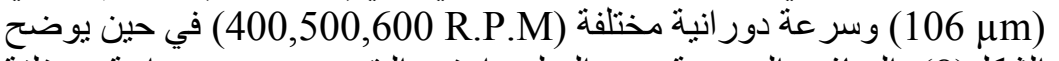
الثكل(8.) النماذج المصنعة من البولي استر النقي وبسرع دور انية مختلفة (400,500,600 R.P.M)

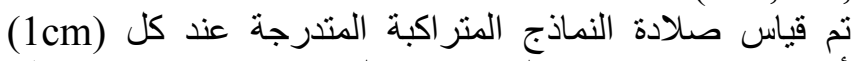

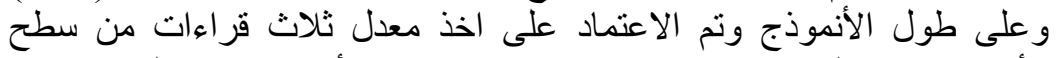

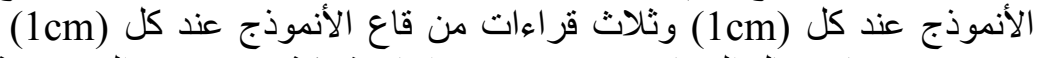

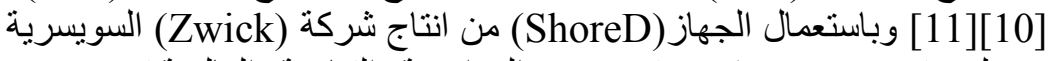

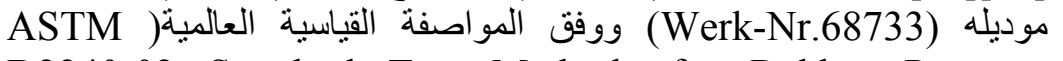
D2240-02 Standard Test Methods for Rubber Property .(Durometer Hardness

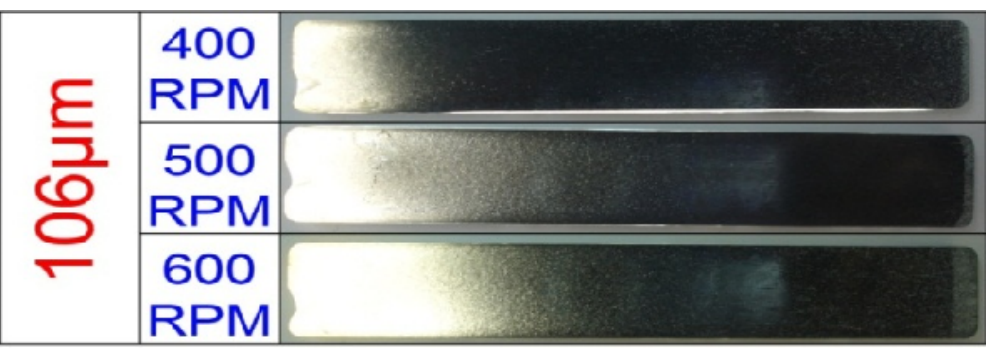

الثكل(7): نماذج المو اد المنر اكبة المتدرجة وظيفياً المصنعة بسرع دور انية مختلفة.

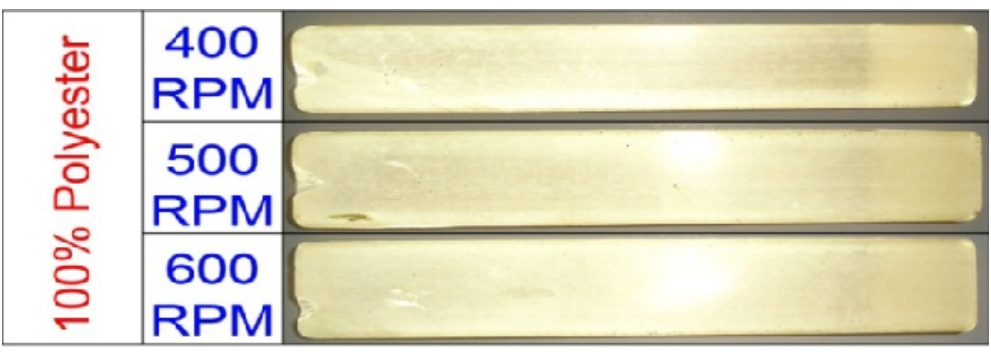

الثكل(8): نماذج البولى استر النقى بسر ع دور انية مختلفة. 
تم تحديد نقاط على طول كل أنموذج مندرج وظيفياً لإيجاد الكسر الحجمي الموضعي عند هذه النقاط

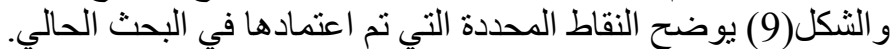

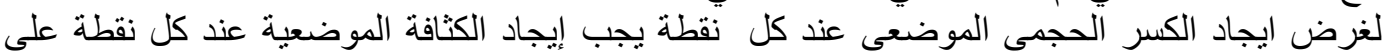

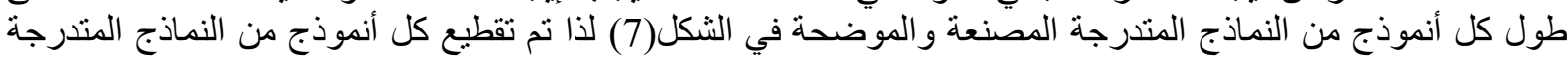

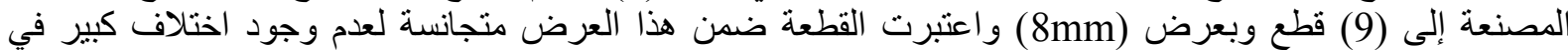

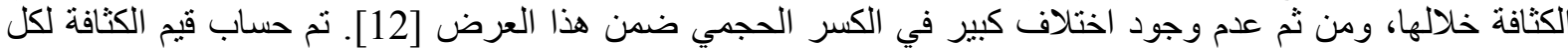
ASTM C693 Standard Test Method For Density of قطعة من القطع وبالاعتماد على المو اصفة القيان Glass By Buoyancy لذلك ميزان الكتروني (Digital Scale) دقته(D) (Denver Instrument) من إنتاج شي شركة الألمانية موديله

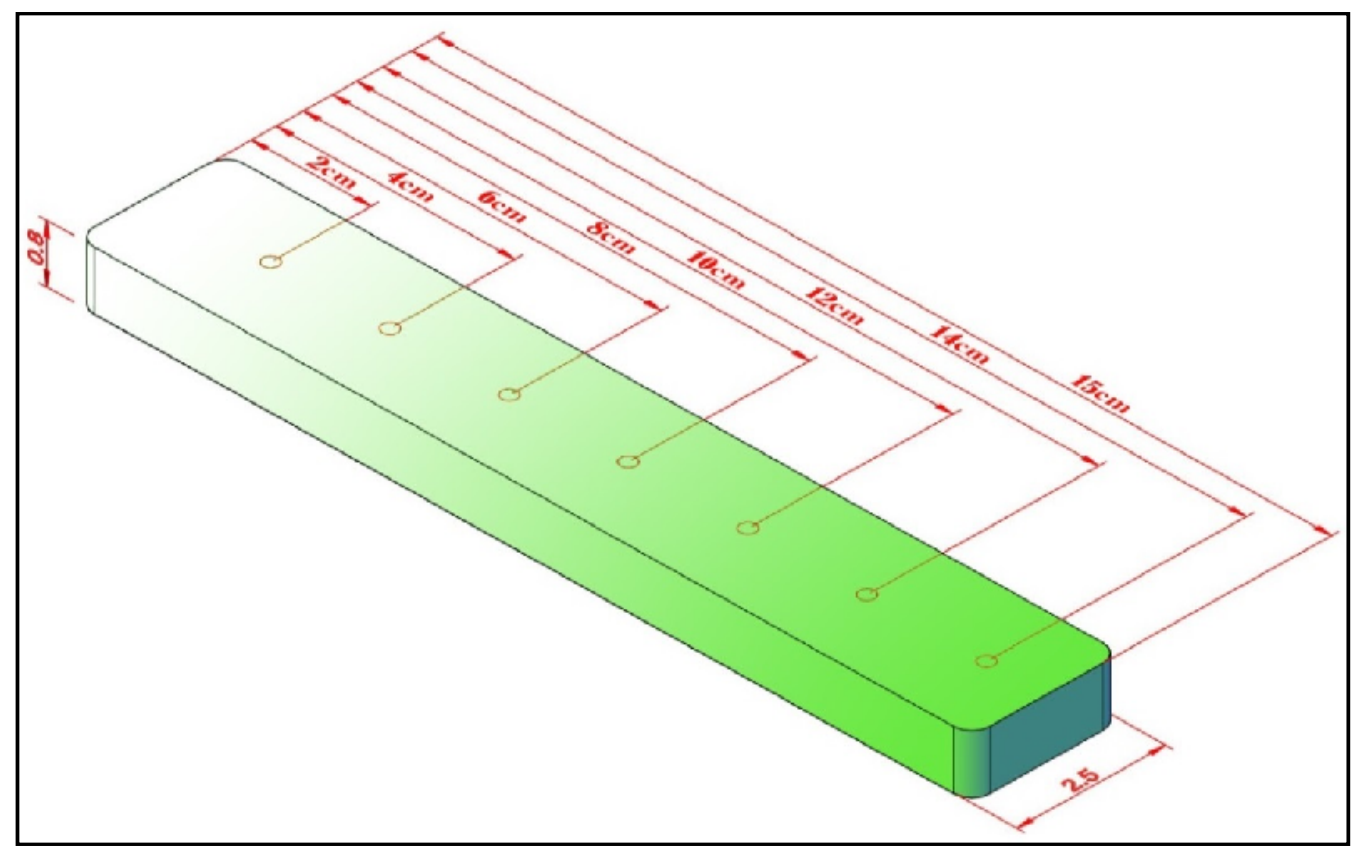

التكل(9): النفاط المحددة على طول الانمودج المتدرج التي تم اعتمادها في البحت

بعد إيجاد كثافة كل قطعة من قطع كل أنموذج متدرج نم حساب كسر ها الحجمي وبالاعتماد على قانون

$\rho_{\mathrm{c}}=\mathrm{V}_{\mathrm{m}}^{r} \rho_{\mathrm{m}}+\mathrm{V}_{\mathrm{p}}^{\mathrm{s}} \rho_{\mathrm{p}}$

الخلائط (Role of Mixture) التالي [12]:

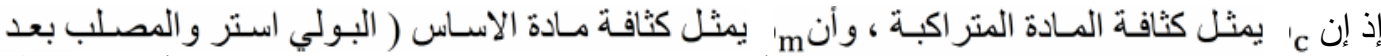

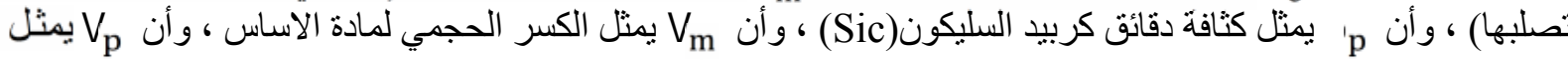

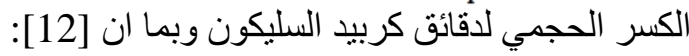

$V_{m}^{T}+V_{p}^{T}=1$

(2) نستطيع ايجاد الكسر الحجمي لدقائق كربيد السليكون لكل قطعة من

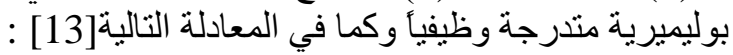

$V_{p}^{r}=\frac{\rho_{c}-\rho_{m}}{\rho_{\mathrm{p}}-\rho_{\mathrm{m}}} \times 100 \%$

م بعد تصلبه وبصورة عملية إذ تم قياس كثافة كل من دقائق كربيد السليكون 


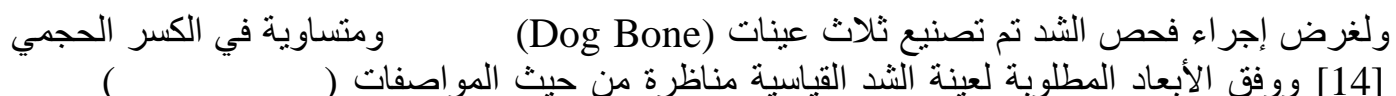

(9) (9) (9) إذ استخدم جهاز

Jinan Shidai Shijin )

مقاره

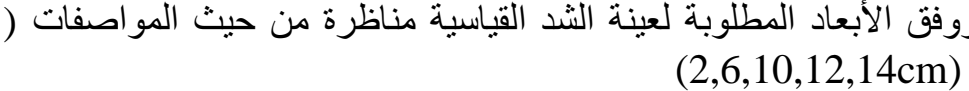

(WDW-200) موديله (Elctronic Universal Test Machine)

الصينية وتم العينات (Testing Machine Group Co., Ltd. (ASTM D638-02a Standard Test Method for Tensile Properties of Plastic) المواصفة القياسية لإجر اء اختبار الثد و الخاصة بفحص المو اد البلاستيكية المعززة وغير المعززة والثكل (10) يوضح أبعاد عينة الثند وفق

عبنات اختبار الثد التي نم تصنيعها هي عبنات من مو اد متر اكبة متجانسة (Homogeneous) مادتها

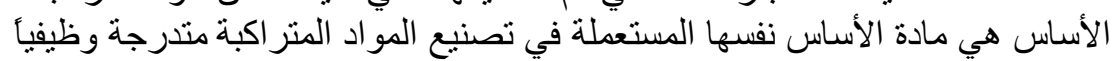

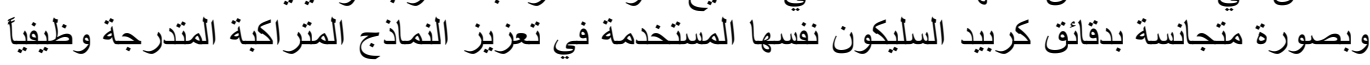

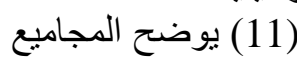

عينات الثد القياسية المتجانسة المصنعة ومو اصفات كل عينة بعد اكتمال تصنيعهاو إخر اجها من الفرن الكهربائي .

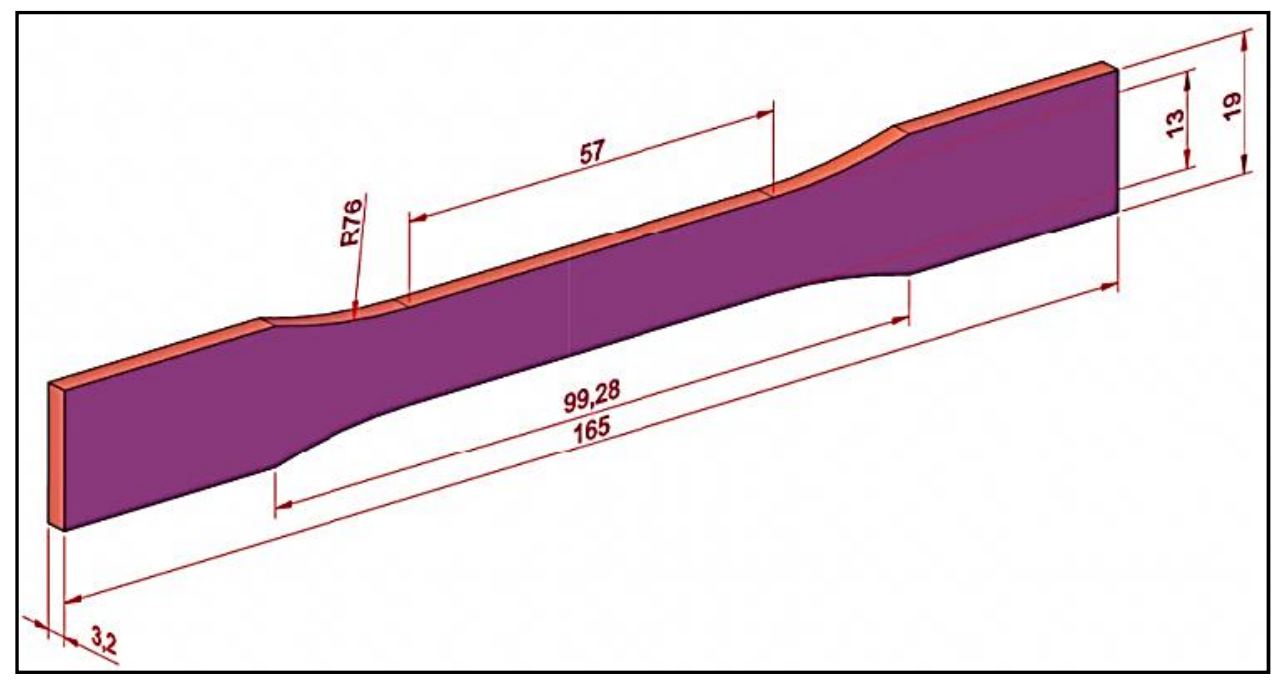

التُكل(10): ابعاد عينة الشّد القياسية (الابعاد بالمليمتر ).

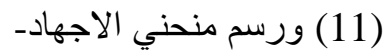

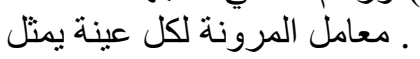

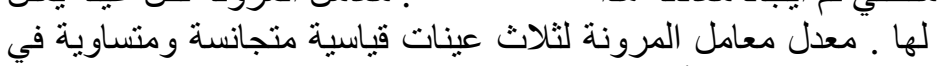

تم إجر اء اختبار الثد للعينات القياسية

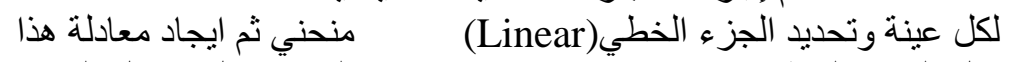

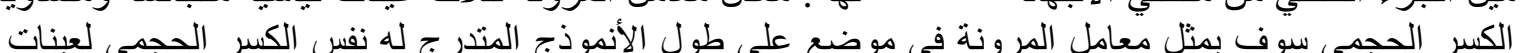

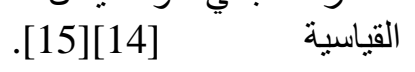

\section{:}

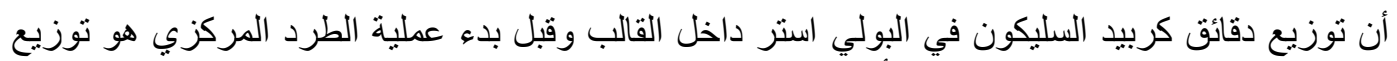

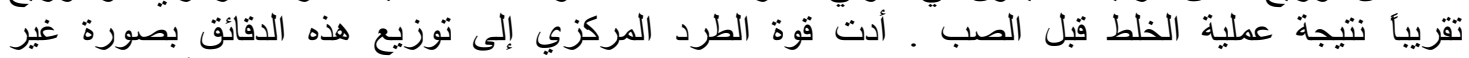

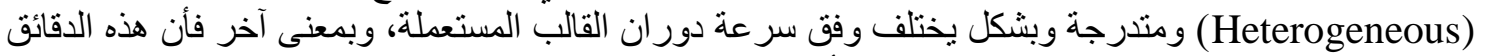

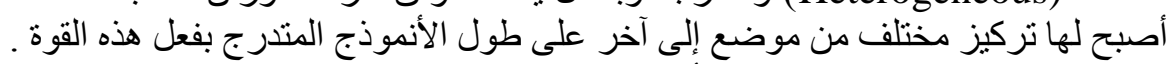

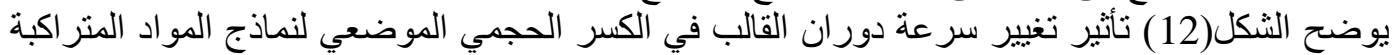

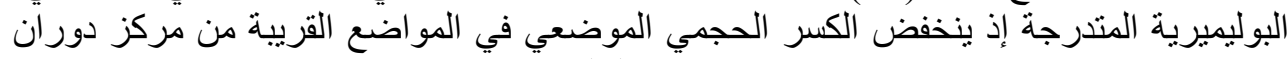

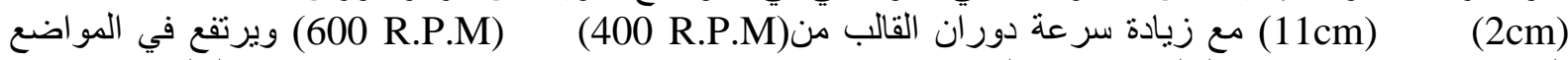

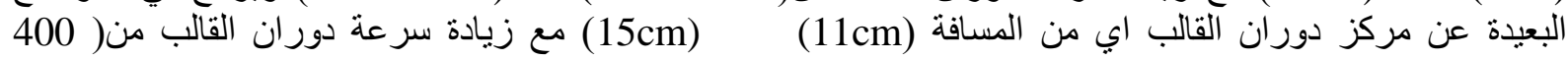


No. 2

April 2015

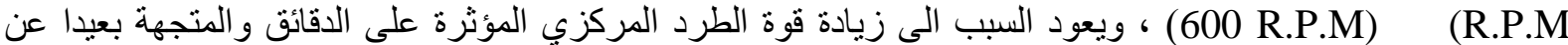

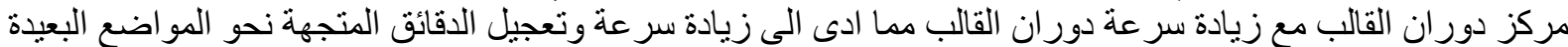

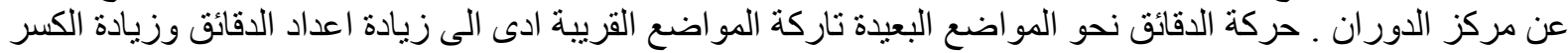

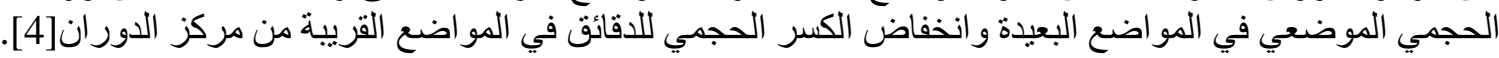

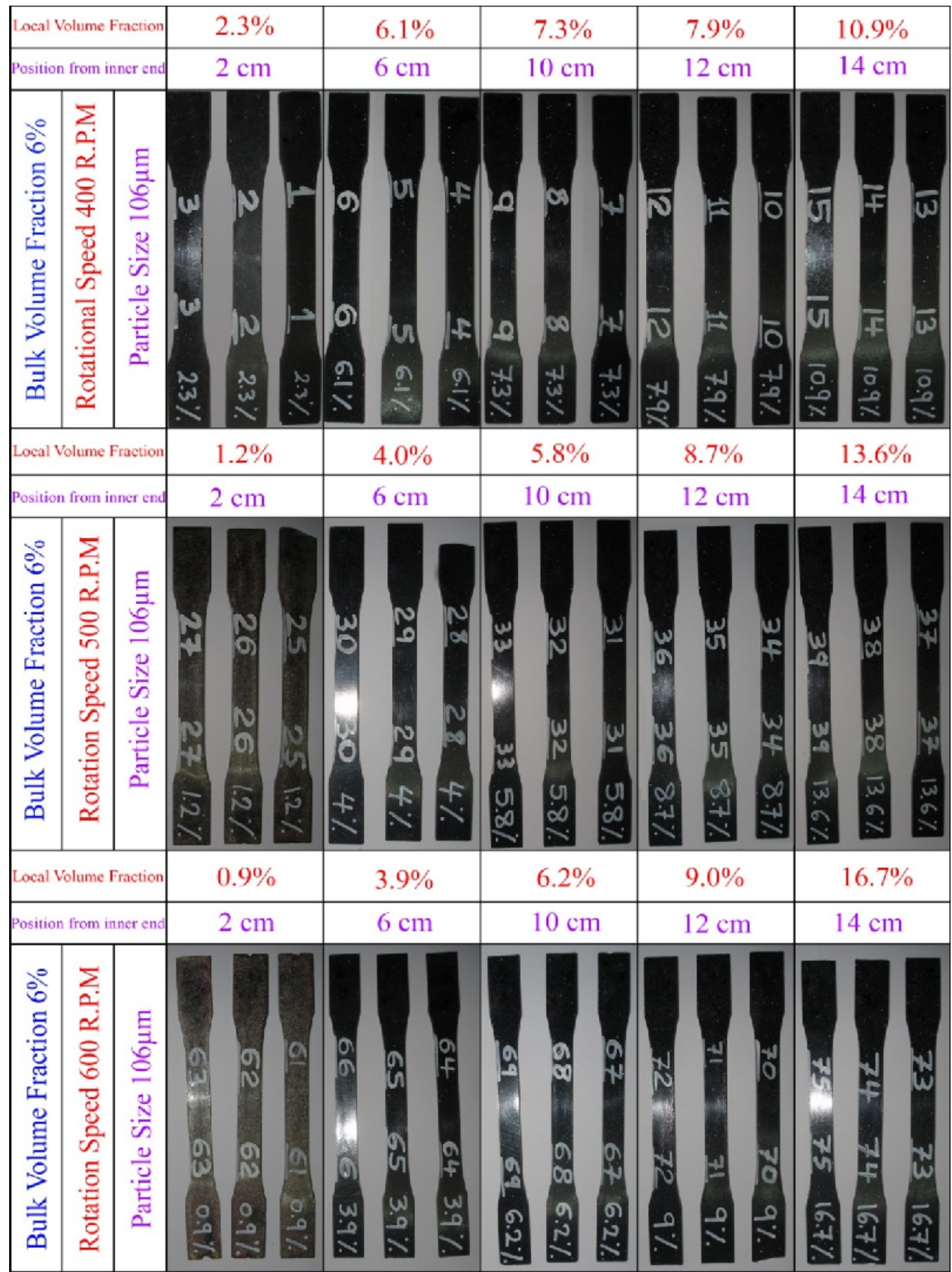

التُكل(11): صور المجاميع التلاتة لعينات التّد القياسية المتجانسة المقابلة للنمادج المتدرجة عند السرع الدور انية (400,500,600 RPM). 
في معدل قيم صلادة شور الموضعية إذ يلاحظ انخفاض قيم

يوضح الثكل(13) نأثير

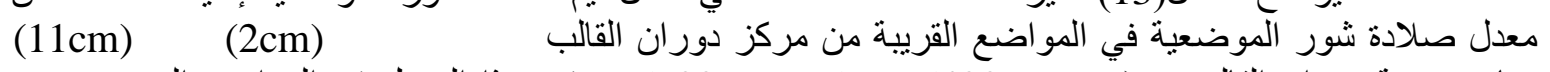

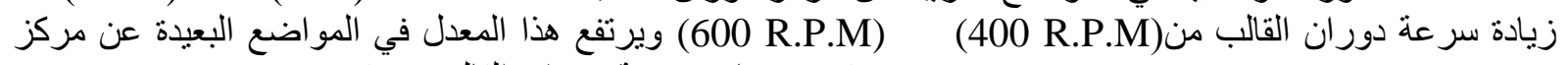

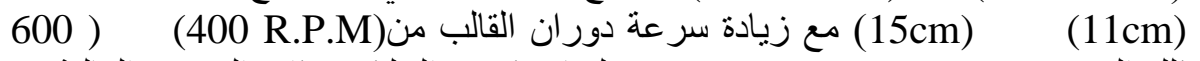

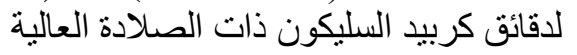

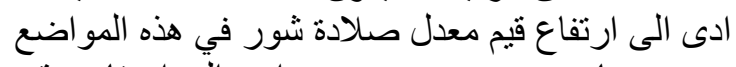

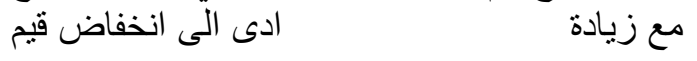

بع.P.M ويرجع السبب في ذلك الى زيادة

هي

ويرجع السبب في ذللك

بع.P.M ويدة جع السبب في ذللك الى ميادة

ان قيم معدل صنادة شئال شور الموضعية

معدل صلادة شور فيها[3] [4] .

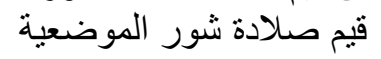

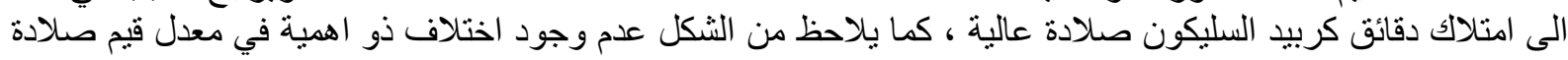
. [9]

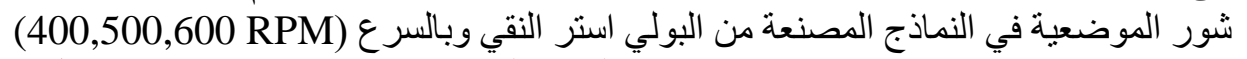
(A,B,C)(14)

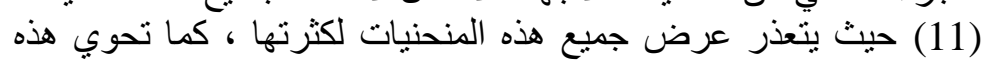

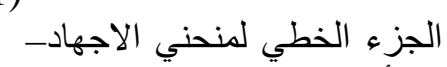

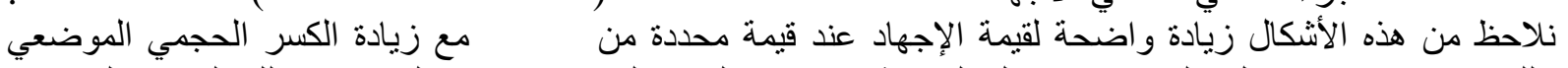

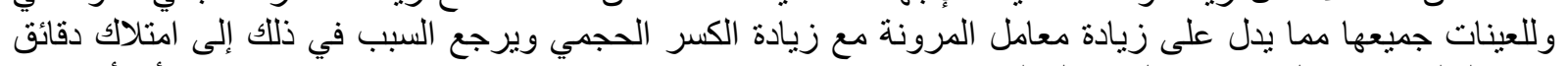
(1.123GPa)

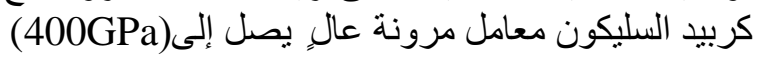

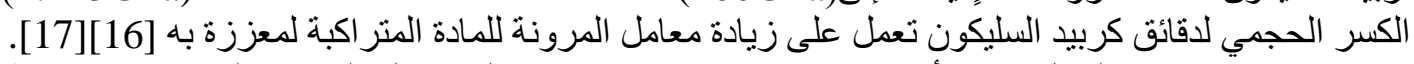

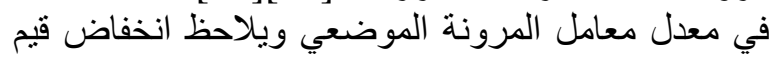

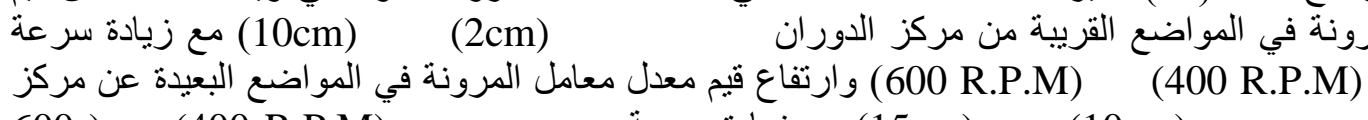

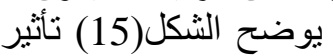

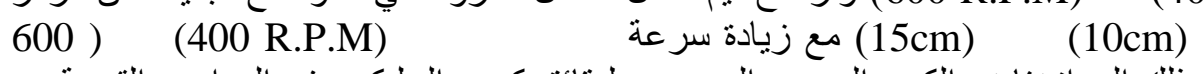

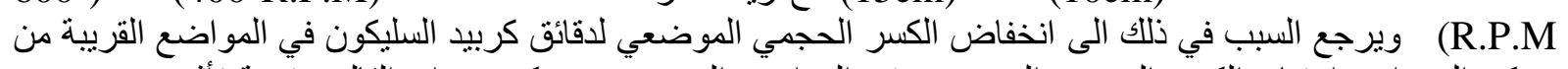

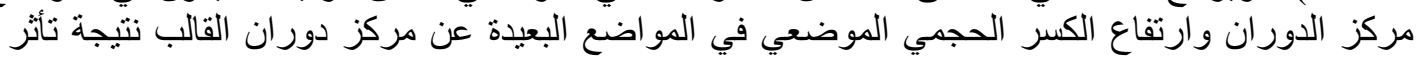
.[12] اكبر مع زيادة - مان

$$
\begin{aligned}
& \text { ان قيم معدل معامل المرونة الموضعي ولنماذج }
\end{aligned}
$$

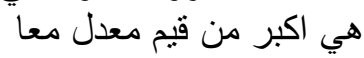

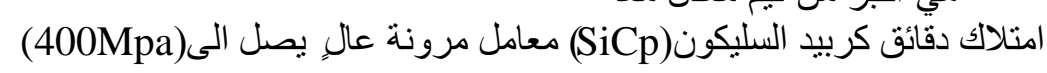

.[14] (1.123GPa)

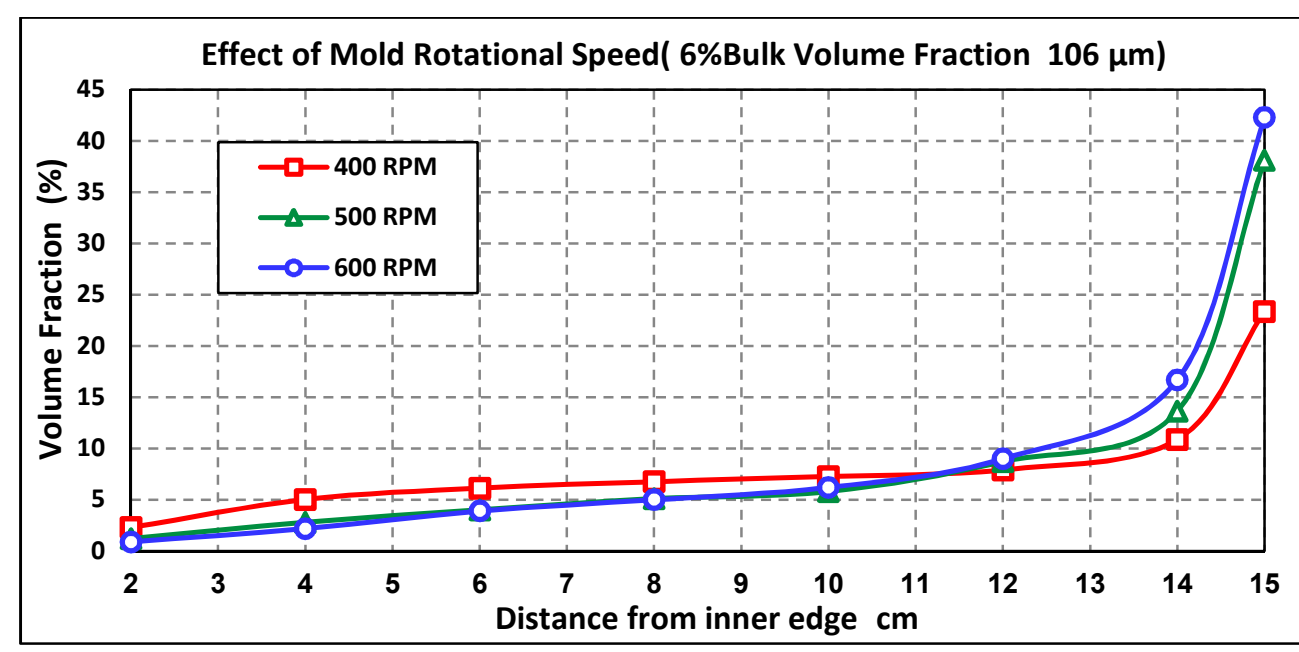

(12) 


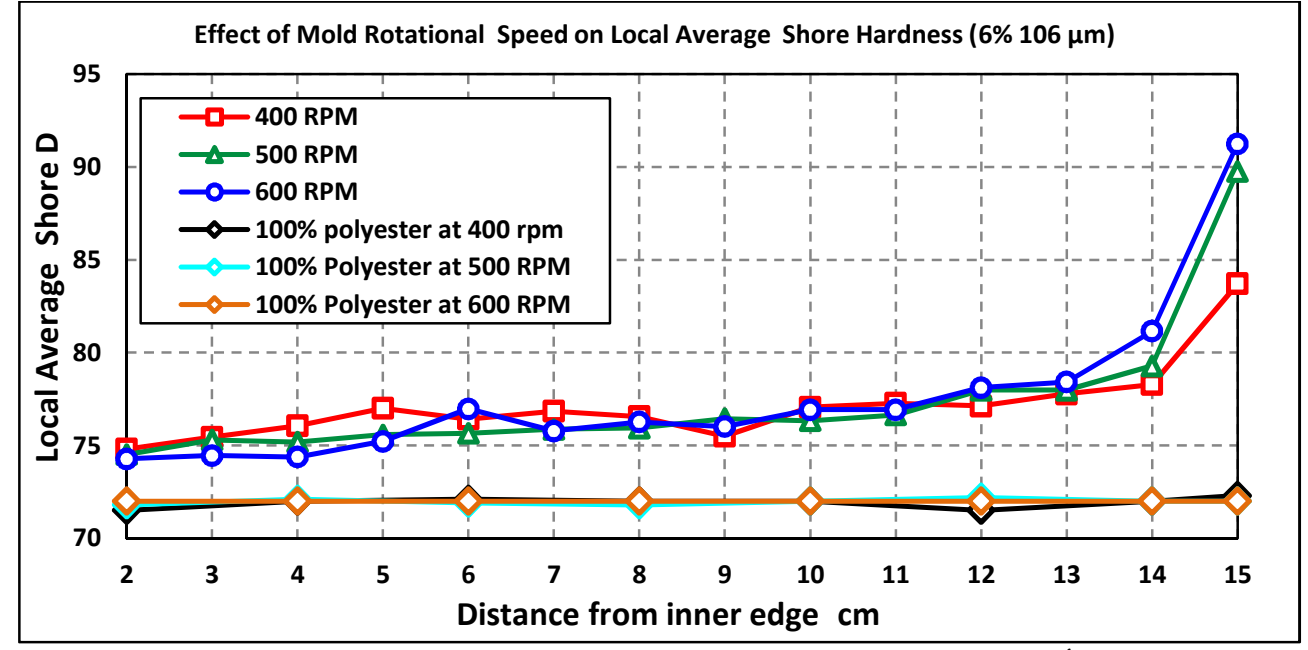

(13): نأثير سر عة دور ان القالب في معدل قيم صلادة شور الموضعية.
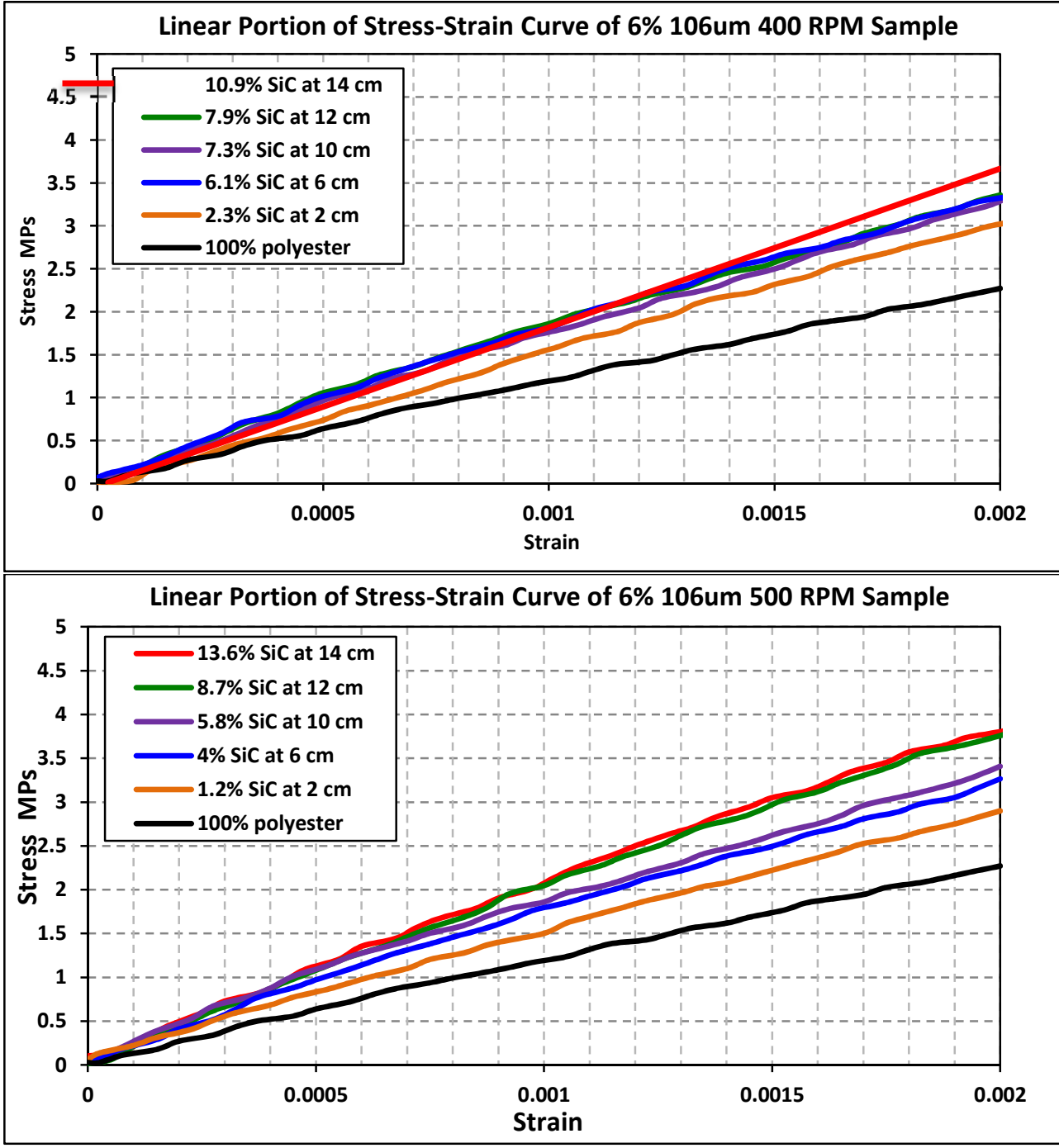
: تأثير سرعة دوران القالب في الخواص الميكانيكية لمواد متراكبة بوليميرية متدرجة وظيفياً
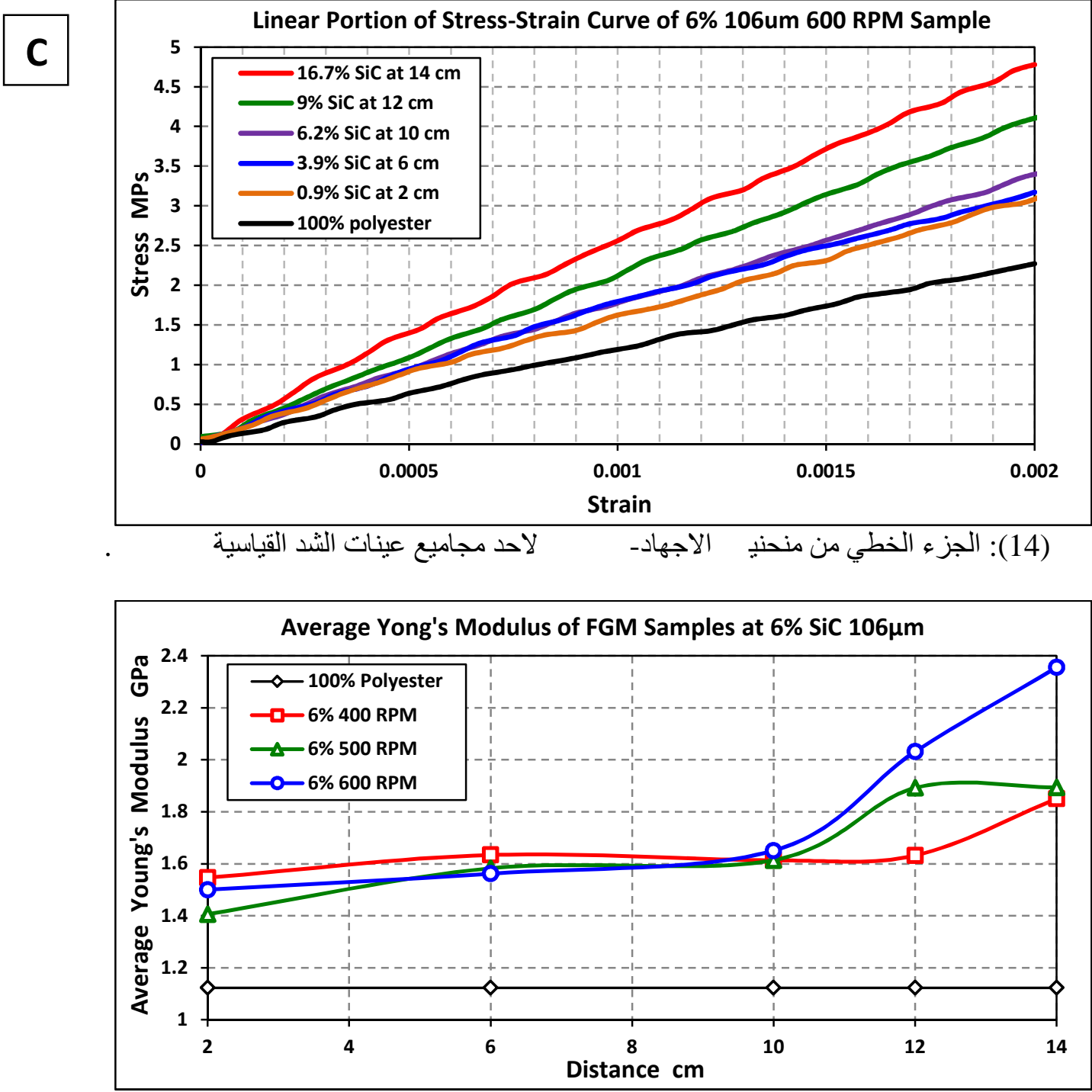

متدرجة وظيفياً. (15)

1. زيادة سرعة دوران القالب في سباكة الطرد المركزي له اثر كبير في الحصول على خصائص ميكانيكية وظيفياً

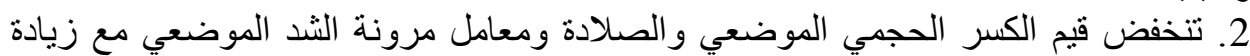

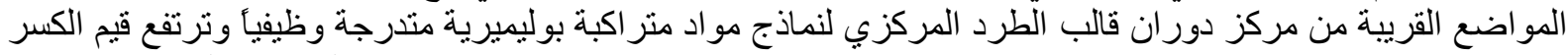

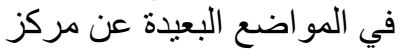
عي مع زيادة 
1 J. Stabik, A. Dybowska*, M. Chomiak," Polymer composites filled with powders as polymer graded materials ", journal of Achievements in Materials and Manufacturing Engineering, Volume 43, Issue 1, November 2010.

2 J. Stabik, M. Chomiak," Influence of casting velocity on surface resistivity of epoxyhard coal graded composites",Archives of Materials Science and Engineering,Volume 47,Issue 1,January 2011,PP48-56.

3 S. M. Elia,"Studying the Effect of Adding Sea Nodules Powders on Flexural Strength and Hardness of Unsaturated Polyester Resin",Eng. \& Tech. Journal ,Volume 29, Issue13 , 2011,PP 2807-2817.

د. نو ال عزت عبد اللطيف، سمير فياض، محسن طالب "در اسة خو اص المو اد المتر اكبة المنتجة بطريقة السباكة

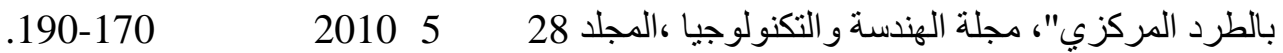

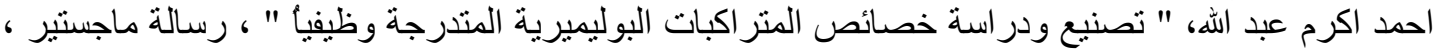
قسم الهندسة الميكانيكية ، جامعة الموصل ودئ ،2013.

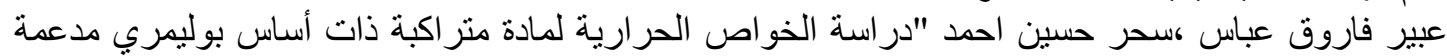

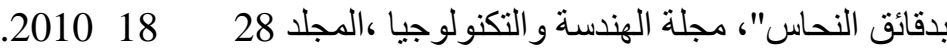

7 J.Murphy,(2001),"Additives for Plastics Handbook",2nd eddition,Elsevier Advance Technology, Oxford,UK,PP 249.

هناء عرير سميج ،"تأثنير التقوية بمسحوق أوكسيد الزنك على الخو اص الميكانيكية لمادة منر اكبة ذات أساس من

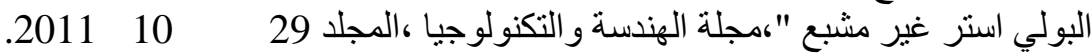

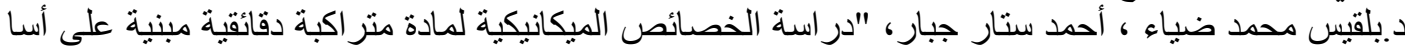

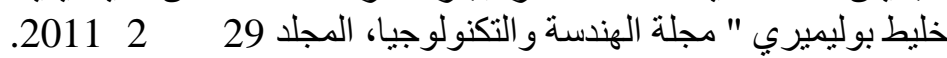

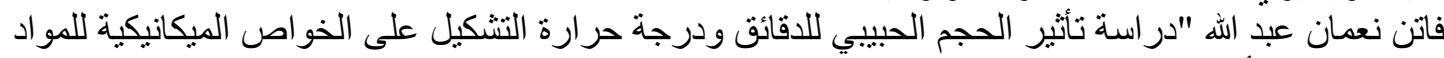

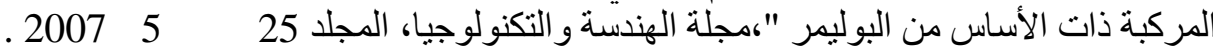

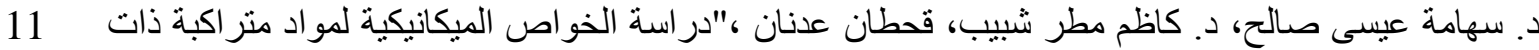

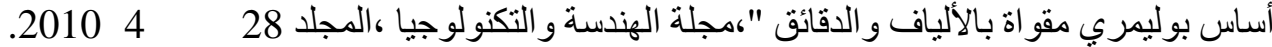

12 N. Gupta , P. K. Rohatgi , T. Matsunaga , ,"Compressive and ultrasonic properties of polyester/fly ash composites",J Mater Sci (2009) 44:1485-1493.

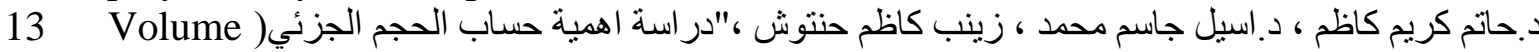
(Fraction .205-195

14 R. J. Butcher, C.E. Rousseau and H. V. Ttippur," A functionally graded particulate composite:preparation, measurements and failure analysis", Elsevier Science, Vol. 47, No. 1, pp. 259-268,1999.

15 P. R. Marur ,H. V. Tippur ,"Evaluation of Mechanical Properties of Functionally Graded Materials",Journal of Testing and Evaluating ,1998.

16 H.A. Kereem,"Study the Influence of Adding Nickel Powder to a Thermosetting Epoxy resin on the Mechanical Properties" ,M.Sc.Thesis,University of Technology ,Baghdad, 2002.

17 A.Jawdat, "Study the Influence of Adding Copper Powder to a Thermosetting Epoxy resin on the Mechanical Properties", M.Sc.Thesis,University of Technology,Baghdad, 2002.

$$
\text { تم اجراء البحث في كلية ألهندسة = جامعة ألموصل }
$$

